\title{
LIPÍDIOS ESTRUTURADOS OBTIDOS A PARTIR DA MISTURA DE GORDURA DE FRANGO, SUA ESTEARINA E TRIACILGLICERÓIS DE CADEIA MÉDIA. II- PONTOS DE AMOLECIMENTO E FUSÃO
}

\author{
Ming Chih Chiu e Luiz Antonio Gioielli* \\ Departamento de Tecnologia Bioquímico-Farmacêutica, Faculdade de Ciências Farmacêuticas, Universidade de São Paulo, \\ Av. Prof. Lineu Prestes, 580, 05508-900 São Paulo - SP, Brasil \\ Renato Grimaldi \\ Departamento de Tecnologia de Alimentos, Faculdade de Engenharia de Alimentos, Universidade Estadual de Campinas, \\ CP 6091, 13081-970 Campinas - SP, Brasil
}

Recebido em 5/12/06; aceito em 17/8/07; publicado na web em 19/12/07

\begin{abstract}
STRUCTURED LIPIDS FROM CHICKEN FAT, ITS STEARIN, AND MEDIUM CHAIN TRIACYLGLYCEROL BLENDS. IISOFTENING AND MELTING POINTS. The aim of the present work is to investigate the effects of blending and chemical interesterification reactions on the softening and melting behavior of chicken fat, its stearin and medium chain triacylglycerols, and blends thereof in various ratios. Chemical interesterification is a promising alternative to the current processes of modifying the physical properties of fats. In the experimental design 7 samples corresponding to 7 different blend proportions were used. The results were represented in triangular diagrams. The addition of stearin influenced the softening and melting points. The mixture response surface methodology proved to be an extremely useful tool for the optimization of the fat mixtures.
\end{abstract}

Keywords: melting point; structured lipid; fat formulation.

\section{INTRODUÇÃO}

A maioria dos óleos e gorduras naturais tem aplicação limitada em suas formas inalteradas, impostas pela sua composição em ácidos graxos e em triacilgliceróis. Para ampliar seu uso, são modificados através de métodos industriais como mistura, fracionamento, interesterificação e hidrogenação ou pela combinação desses pro$\operatorname{cessos}^{1}$. A alteração das características físicas naturais de um óleo ou gordura proporciona maior funcionalidade para um grande número de formulações de produtos alimentícios ${ }^{2}$.

Mistura é o método mais simples de modificação de óleos e gorduras. Os requisitos para a aplicação de gorduras em diversos produtos têm se tornado cada vez mais sofisticados. Contudo, há poucas formas pelas quais as especificações adequadas podem ser atingidas simplesmente utilizando-se a mistura de óleos e gorduras naturais. Outras técnicas de modificação precisam ser utilizadas para um ou mais componentes da mistura a fim de alcançar as especificações comerciais dos produtos a um menor custo ${ }^{3}$. A hidrogenação de óleos vegetais polinsaturados é atualmente menos atraente, devido às evidências de que os ácidos graxos trans apresentam efeitos nutricionais adversos ${ }^{4}$. A interesterificação tem recebido grande atenção da indústria de modificação de óleos comestíveis como um método alternativo para melhorar as propriedades físico-químicas dos óleos e gorduras².

Lipídios estruturados são definidos como triacilgliceróis reestruturados ou modificados obtidos através de interesterificação química ou enzimática, ou ainda por engenharia genética, com a finalidade de alterar a composição em ácidos graxos e/ou sua distribuição nos triacilgliceróis. São sintetizados com o objetivo de obter lipídios nutracêuticos ou funcionais, que podem proporcionar benefícios específicos para a saúde, bem como melhorar as características físicas e químicas dos triacilgliceróis, além de alterar ou incrementar as propriedades nutricionais dos alimentos ${ }^{5-7}$. Entre as diversas possibi-

*e-mail: lagio@usp.br lidades, eles podem ser sintetizados com o propósito de melhorar ou modificar as características físicas (polimorfismo, pontos de amolecimento e de fusão, conteúdo de gordura sólida, viscosidade e consistência) e/ou químicas (estabilidade oxidativa) dos triacilgliceróis, bem como para modificar uma ou mais propriedades nutricionais (presença ou ausência de ácidos graxos saturados ou ácidos graxos insaturados de fácil absorção e digestão). Com o aumento do conhecimento sobre os efeitos dos ácidos graxos relacionados ao comprimento de cadeia carbônica, grau de insaturação e distribuição estereoespecífica dos ácidos graxos nos triacilgliceróis no metabolismo e saúde, há crescente interesse em usar lipídios estruturados para a redução do risco de doenças, bem como para a melhoria da saúde ${ }^{7,8}$.

Os alimentos funcionais, dos quais os lipídios estruturados fazem parte, são alimentos ou ingredientes que podem proporcionar um efeito benéfico à saúde, além dos nutrientes básicos que contêm ${ }^{5}$. Além disso, estes lipídios apresentam a vantagem de não possuírem ácidos graxos trans em sua estrutura molecular, ao contrário do que ocorre com as gorduras parcialmente hidrogenadas?.

Segundo Chiu e Gioielli ${ }^{10,11}$, a gordura de frango apresenta-se líquida ou semi-líquida à temperatura ambiente, podendo ser utilizada para diversos fins alimentícios, tais como condimentos, bolos e frituras. Além disso, também pode ser utilizada para melhorar a consistência de cremes cosméticos.

Lee e Foglia ${ }^{12}$ pesquisaram a modificação da gordura de frango através da incorporação do ácido caprílico aos seus triacilgliceróis a fim de produzir lipídios estruturados, obtidos por interesterificação. Estes lipídios funcionais apresentaram em sua composição ácidos graxos monoinsaturados e ácidos graxos de cadeia média. Os ácidos graxos saturados na gordura de frango estão principalmente localizados nas posições $s n-1$ e $s n-3$ dos triacilgliceróis, podendo ser seletivamente substituídos por ácidos graxos nutricionalmente desejáveis através da acidólise enzimática, utilizando-se lipase $s n$ 1,3-regioseletiva.

Vários triacilgliceróis específicos têm sido sintetizados para pesquisas sobre metabolismo, absorção e incorporação tecidual. 
Contudo, uma vez que experiências com triacilgliceróis estruturados em nutrição humana são limitadas, muitos dos efeitos destes lipídios devem ser deduzidos a partir dos componentes individuais, como, por exemplo, dos ácidos graxos de cadeia curta, média e longa baseados em experimentos in vitro e in vivo. Os triacilgliceróis de cadeia média são amplamente aplicados em nutrição clínica, e algumas precauções e vantagens em relação às futuras aplicações dos triacilgliceróis estruturados estão baseadas em experiências obtidas com os triacilgliceróis de cadeia média ${ }^{13}$.

A metodologia de superfície de resposta constitui o conjunto de técnicas de otimização extensivamente utilizado em ciência e tecnologia dos alimentos, possivelmente porque sua teoria é completa e também simples e eficiente ${ }^{14,15}$.

Os objetivos deste trabalho foram sintetizar lipídios estruturados a partir de gordura de frango, sua estearina e triacilgliceróis de cadeia média através da reação de interesterificação química, e caracterizálos através da análise de suas propriedades físico-químicas.

\section{PARTE EXPERIMENTAL}

\section{Material}

A gordura de frango foi obtida após fusão da gordura abdominal à temperatura de $90-100^{\circ} \mathrm{C}$, eliminando colágenos através da filtração e a fração líquida através da decantação. A seguir, $2 \mathrm{~kg}$ da amostra de gordura foram colocados em recipientes de vidro e armazenados a temperatura de $-20{ }^{\circ} \mathrm{C}$.

A estearina de frango utilizada foi obtida segundo o processo descrito em trabalho anterior ${ }^{16}$ e os triacilgliceróis de cadeia média da marca Trigliceril ${ }^{\circledR}$ (mistura de triacilgliceróis compostos principalmente pelos ácidos graxos caprílico e cáprico) foram adquiridos no comércio. Para a reação de interesterificação química foi utilizado metóxido de sódio (Merck) como catalisador.

\section{Mistura}

Os procedimentos de mistura foram realizados de acordo com o processo descrito em trabalho anterior ${ }^{16}$, nas proporções apresentadas na Tabela 1.

Tabela 1. Planejamento experimental centróide simplex de misturas

\begin{tabular}{lccc}
\hline Amostra $\left(\mathrm{n}^{\mathrm{o}}\right)$ & \multicolumn{3}{c}{ Componentes (proporção $\mathrm{m} / \mathrm{m}$ ) } \\
& $\mathrm{x}_{1}$ & $\mathrm{x}_{2}$ & $\mathrm{x}_{3}$ \\
\hline 1 & 1 & 0 & 0 \\
2 & 0 & 1 & 0 \\
3 & 0 & 0 & 1 \\
4 & $1 / 2$ & $1 / 2$ & 0 \\
5 & $1 / 2$ & 0 & $1 / 2$ \\
6 & 0 & $1 / 2$ & $1 / 2$ \\
7 & $1 / 3$ & $1 / 3$ & $1 / 3$ \\
8 & $2 / 3$ & $1 / 6$ & $1 / 6$ \\
9 & $1 / 6$ & $2 / 3$ & $1 / 6$ \\
10 & $1 / 6$ & $1 / 6$ & $2 / 3$ \\
\hline
\end{tabular}

$\mathrm{x}_{1}=$ gordura abdominal de frango $(\mathrm{GF}) ; \mathrm{x}_{2}=$ estearina de gordura de frango (EGF); $x_{3}=$ triacilgliceróis de cadeia média (TCM)

\section{Interesterificação química}

A interesterificação química foi realizada conforme o processo descrito em trabalho anterior ${ }^{16}$.

\section{Ponto de amolecimento}

O ponto de amolecimento das amostras foi determinado pelo método do tubo capilar aberto, imerso em água sob agitação e aquecimento, de acordo com o método oficial Cc 3-25 da AOCS ${ }^{17}$. As amostras foram analisadas em triplicata.

\section{Ponto de fusão}

O ponto de fusão das amostras foi determinado pelo método do tubo capilar fechado, imerso em água sob agitação e aquecimento, de acordo com o método oficial Cc 1-25 da AOCS ${ }^{17}$. As amostras foram analisadas em triplicata.

\section{Análise térmica}

A análise térmica das amostras foi realizada por calorimetria diferencial de varredura (DSC) conforme o método $\mathrm{AOCS}^{17} \mathrm{Cj} 1$ 94. O equipamento utilizado foi o analisador térmico DSC 7 da Perkin Elmer acoplado ao Thermal Analysis Controller Cooler TAC 7/DX. O sistema de manuseio de dados utilizado foi o Software Pyris Series Thermal Analysis System. As condições de análise foram: peso da amostra: $10 \mathrm{mg}$; curvas de fusão: $10 \mathrm{~min}\left(80{ }^{\circ} \mathrm{C}\right), 80$ ${ }^{\circ} \mathrm{C}$ a $-40{ }^{\circ} \mathrm{C}\left(10^{\circ} \mathrm{C} / \mathrm{min}\right) ; 30 \mathrm{~min}$ a $-40{ }^{\circ} \mathrm{C} ;-40{ }^{\circ} \mathrm{C}$ a $80{ }^{\circ} \mathrm{C}\left(5^{\circ} \mathrm{C} /\right.$ $\min )$.

\section{Análise estatística}

Para as respostas analíticas foi aplicado um modelo de regressão múltipla, do tipo cúbico especial ${ }^{18}$, representado pela seguinte equação:

$y=\beta_{1} x_{1}+\beta_{2} x_{2}+\beta_{3} x_{3}+\beta_{12} x_{1} x_{2}+\beta_{13} x_{1} x_{3}+\beta_{23} x_{2} x_{3}+\beta_{123} x_{1} x_{2} x_{3}$

onde: $y=$ resposta; $\beta=$ coeficientes gerados por regressão múltipla; $\mathrm{x}=$ proporção dos componentes

Foi utilizado o aplicativo Statistica $2002^{19}$, que permitiu a obtenção dos coeficientes para o modelo, além de apresentar seus níveis de significância, coeficientes de determinação e análise de variância.

\section{RESULTADOS E DISCUSSÃO}

As Figuras 1 e 2 mostram os pontos de amolecimento e fusão para as amostras individuais e para as misturas binárias e ternárias da gordura abdominal de frango, sua estearina e triacilgliceróis de cadeia média antes e após a interesterificação química. Os resultados indicam a existência de ampla faixa de variação de pontos de amolecimento e fusão nas amostras estudadas. Estes parâmetros não foram determinados para o TCM pelo método do tubo capilar, pois este não se aplica a esta amostra, devido ao seu baixo ponto de fusão. A análise do ponto de fusão do TCM foi realizada pelo método de DSC. O ponto de fusão dos ácidos graxos de cadeia média (AGCM) é muito mais baixo $\left(\mathrm{C} 6: 0:-3,2{ }^{\circ} \mathrm{C}\right.$; $\mathrm{C} 8: 0: 6,5^{\circ} \mathrm{C}$; $\mathrm{C} 10: 0$ : $31,3{ }^{\circ} \mathrm{C}$ ) que o dos ácidos graxos de cadeia longa (AGCL) (C16:0: 63, ${ }^{\circ} \mathrm{C}$; C18:0: $72,0{ }^{\circ} \mathrm{C}$ ). Portanto, os AGCM e os TCM são líquidos à temperatura ambiente ${ }^{20}$.

Os pontos de amolecimento e fusão das misturas binárias e ternárias (amostras 4 a 10 antes da reação de interesterificação) variaram de acordo com as interações ocorridas entre os componentes das amostras. As misturas binárias e ternárias apresentaram dois grupos distintos de triacilgliceróis que continham 22 a 30 e 48 a 54 átomos de carbono ${ }^{16}$. Isso demonstra que o processo de mistura é 


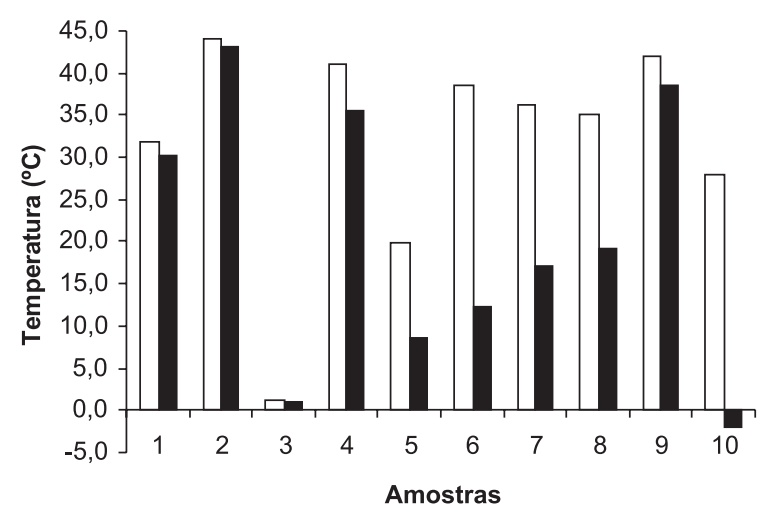

$\square$ Ponto de Amolecimento (antes) — Ponto de Amolecimento (após)

Figura 1. Pontos de amolecimento das gorduras individuais e das misturas binárias e ternárias, antes e após a interesterificação química

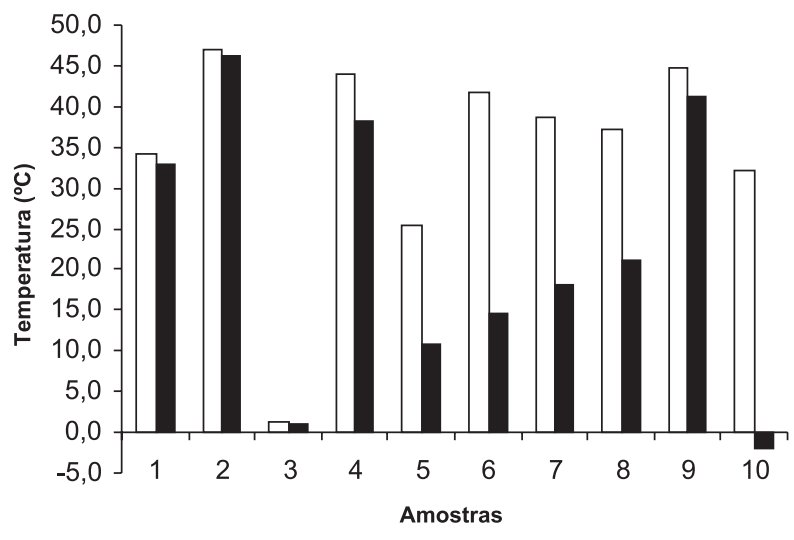

$\square$ Ponto de Fusão (antes) $\square$ Ponto de Fusão (após)

Figura 2. Pontos de fusão das gorduras individuais e das misturas binárias e ternárias, antes e após a interesterificação química

um método físico de pequena modificação de óleos e gorduras e que não provoca implicações metabólicas de grande impacto quando comparado ao efeito causado pela interesterificação ${ }^{2,16}$.

As gorduras e óleos naturais de origem vegetal ou animal são misturas de triacilgliceróis e outras substâncias e consistem em grande número de componentes que passam por estágios graduais de amolecimento antes de se tornarem completamente líquidas ${ }^{20}$.

Os valores dos pontos de fusão e amolecimento das amostras 1 (gordura de frango) e 2 (estearina) antes da reação estão de acordo com os encontrados por Chiu et al. ${ }^{21}$ para os mesmos materiais analisados.

Não houve mudanças significativas nos pontos de amolecimento e fusão após a interesterificação química para as amostras 1, 2 e 3. Contudo, para os lipídios estruturados (amostras 4 a 10) os pontos de amolecimento e fusão sofreram queda acentuada após a reação, como pode ser observado nas Figuras 1 e 2. Esta diminuição é decorrente da incorporação de ácidos graxos de cadeia média, formando triacilgliceróis com 32 a 46 átomos de carbono e de baixo ponto de fusão. O ponto de fusão variou conforme o comprimento da cadeia carbônica dos ácidos graxos saturados, sendo maior para cadeias carbônicas mais longas ${ }^{16}$.

Para os lipídios estruturados, as espécies de triacilgliceróis foram separadas em três grupos distintos com número de átomos de carbono nas faixas de 22 a 30, 32 a 46 e 48 a 54. Quando os TCM foram incorporados aos lipídios estruturados houve a formação do grupo com 32 a 46 carbonos, caracterizando um lipídio estruturado composto por ácidos graxos de cadeia média e por um ácido graxo de cadeia longa proveniente da gordura de frango. Este tipo de triacilglicerol pode ser designado como MML ( $\mathrm{M}=$ ácido graxo de cadeia média, $\mathrm{L}$ = ácido graxo de cadeia longa). Os grupos de triacilgliceróis que continham de 22 a 30 carbonos foram formados por TCM e os que apresentaram de 48 a 54 carbonos foram provenientes da gordura de frango ${ }^{16}$.

O processo de interesterificação permite alterar a distribuição dos ácidos graxos nos triacilgliceróis, formando produtos com características de fusão e cristalização diferentes dos óleos e gorduras originais $^{22}$.

A Tabela 2 apresenta os coeficientes calculados por regressão múltipla a partir dos resultados experimentais das amostras 1 a 7 dos pontos de amolecimento e fusão antes e após a reação de interesterificação. Os coeficientes não-significativos $(p>0,05)$ foram eliminados.

Tabela 2. Coeficientes calculados por regressão múltipla a partir dos resultados experimentais das amostras 1 a 7 dos pontos de amolecimento (PA) e fusão (PF) antes e após a reação de interesterificação química $(\mathrm{p}<0,05)$

\begin{tabular}{lcccccccc}
\hline Resultados & \multicolumn{10}{c}{ Coeficientes } \\
\cline { 2 - 9 } & $\beta_{1}$ & $\beta_{2}$ & $\beta_{3}$ & $\beta_{12}$ & $\beta_{13}$ & $\beta_{23}$ & $\beta_{123}$ & $\mathrm{R}^{2}$ \\
\hline PA antes & 31,75 & 44,07 & 0 & 14,08 & 14,88 & 64,28 & 0 & 0,999 \\
PA após & 30,05 & 42,85 & 0 & 0 & $-38,33$ & $-35,93$ & 0 & 0,998 \\
PF antes & 35,15 & 47,87 & 0 & 0 & 28,22 & 66,42 & 0 & 0,995 \\
PF após & 32,38 & 45,68 & 0 & 0 & $-28,95$ & $-39,82$ & 0 & 0,997 \\
\hline
\end{tabular}

A análise de regressão demonstrou que o melhor ajuste para as misturas e para os lipídios estruturados foi obtido com o modelo quadrático, que apresentou interação entre as variáveis. As respostas analisadas não dependeram das interações ternárias para nenhuma das propriedades analisadas antes e após a reação. No caso das interações binárias entre gordura de frango e sua estearina, com exceção do ponto de amolecimento antes da interesterificação, os coeficientes $\beta_{12}$ não foram significativos.

Os pontos de amolecimento e fusão antes e após a reação dependeram da gordura de frango, de sua estearina, e das interações binárias entre estearina e TCM, e entre a gordura de frango e TCM. Observa-se que a amostra 3 (TCM), sendo o componente líquido, não contribuiu estatisticamente para os pontos de amolecimento e fusão antes e após a reação. As interações entre a estearina e o TCM, e a gordura de frango e TCM apresentaram coeficientes positivos para os pontos de amolecimento e fusão antes da reação, porque estas propriedades dependem da passagem dos triacilgliceróis de maior ponto de fusão do estado sólido para o estado líquido. Estes triacilgliceróis continuaram influenciando as referidas propriedades mesmo quando o teor de TCM chegou até a 50\% (amostra 6). Por outro lado, estas mesmas interações, após a interesterificação, apresentaram coeficientes negativos, que podem ser explicados devido ao efeito eutético, que representa incompatibilidade no estado sólido entre os triacilgliceróis componentes ${ }^{10,11,20,23-25}$.

Os modelos estatísticos para os pontos de amolecimento e fusão das misturas e dos lipídios estruturados estão representados nas Figuras 3 a 6 em diagramas triangulares, onde foram indicadas as curvas de nível (linhas ligando pontos de resposta de igual valor). Os três vértices correspondem às respostas das gorduras de frango, sua estearina e dos triacilgliceróis de cadeia média originais. Os pontos sobre os lados do triângulo eqüilátero representam os resultados das misturas binárias. Na região interna, encontram-se as res- 
postas referentes às misturas ternárias. Para a determinação da proporção dos componentes de qualquer ponto interno, devem ser traçadas retas paralelas aos três lados do triângulo, no cruzamento das respectivas paralelas opostas a cada vértice ${ }^{20,26,27}$.

Os diagramas triangulares permitem encontrar uma mistura ótima ou escolher entre misturas alternativas, dependendo de considerações econômicas ou de outra ordem, como disponibilidade das matérias-primas ${ }^{18,23,26-28}$.

As equações do modelo empírico obtido a partir das amostras 1 a 7 para as propriedades ponto de amolecimento (PA) e ponto de fusão (PF) das misturas e dos lipídios estruturados em função das variáveis gordura de frango $(\mathrm{GF})$, estearina $(\mathrm{EF})$ e triacilgliceróis de cadeia média (TCM) são apresentadas a seguir:

Modelo empírico obtido por regressão múltipla para o ponto de amolecimento antes e após a interesterificação

$\mathrm{PA}=31,75 * \mathrm{GF}+44,07 * \mathrm{EF}+14,08 * \mathrm{GF} * \mathrm{EF}+14,88 * \mathrm{GF} * \mathrm{TCM}+$ $64,28 * \mathrm{EF} * \mathrm{TCM}$ (antes)

$\mathrm{PA}=30,05 * \mathrm{GF}+42,85 * \mathrm{EF}-38,33 * \mathrm{GF} * \mathrm{TCM}-35,93 * \mathrm{EF} * \mathrm{TCM}$ (após)

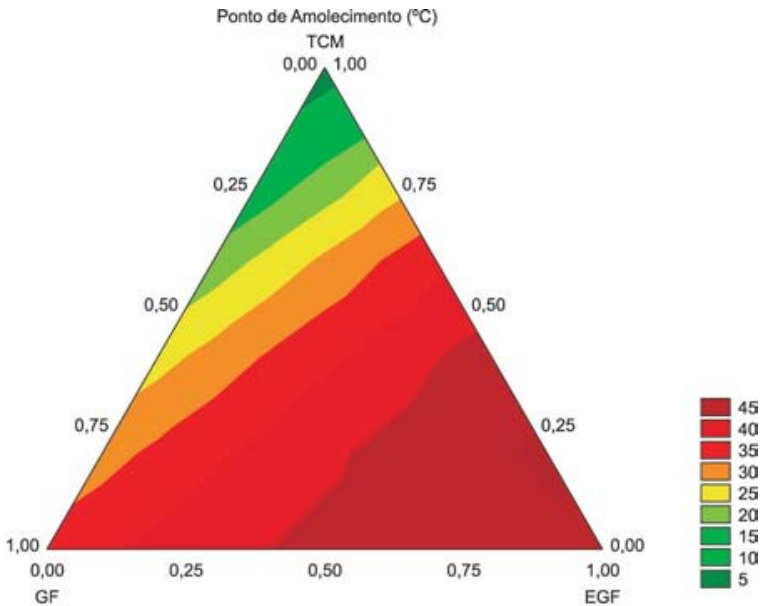

Figura 3. Diagrama triangular do ponto de amolecimento das amostras individuais e para as misturas binárias e ternárias da gordura abdominal de frango $(G F)$, sua estearina (EGF) e triacilgliceróis de cadeia média (TCM)

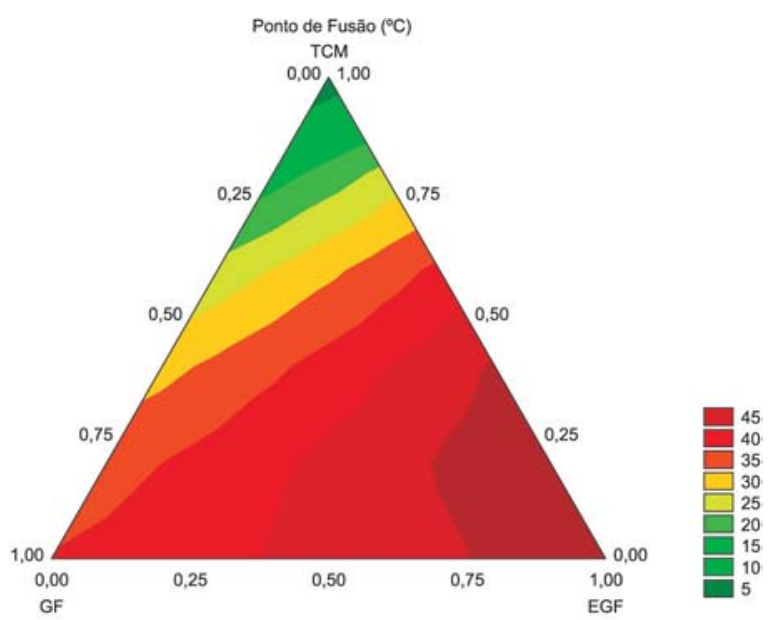

Figura 4. Diagrama triangular do ponto de fusão das amostras individuais e para as misturas binárias e ternárias da gordura abdominal de frango $(G F)$, sua estearina (EGF) e triacilgliceróis de cadeia média (TCM)

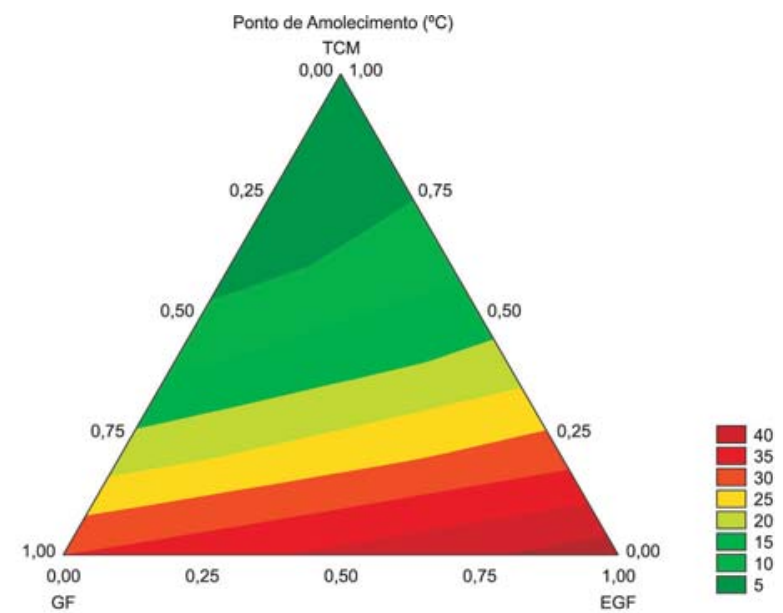

Figura 5. Diagrama triangular do ponto de amolecimento para os lipídios estruturados. Gordura abdominal de frango (GF); Estearina (EGF); Triacilgliceróis de cadeia média (TCM)

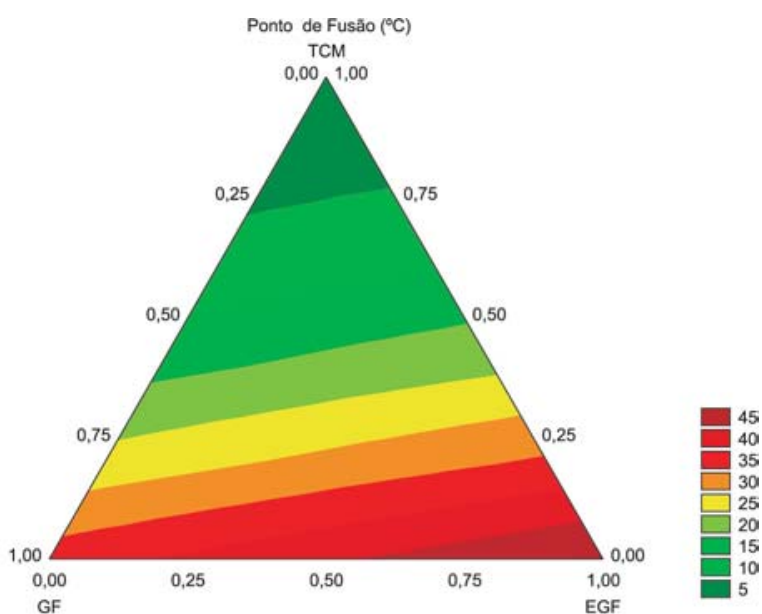

Figura 6. Diagrama triangular do ponto de fusão para os lipídios estruturados. Gordura abdominal de frango (GF) Estearina (EGF) Triacilgliceróis de cadeia média (TCM)

Modelo empírico obtido por regressão múltipla para o ponto de fusão antes e após a interesterificação

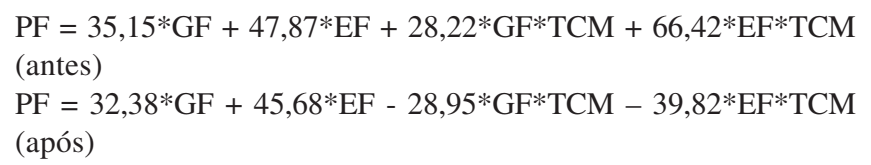

Na Tabela 3 encontram-se os valores dos pontos de amolecimento e de fusão experimentais das amostras 8,9 e 10 e os valores calculados pelos modelos empíricos obtidos antes e após a interesterificação. As amostras 8, 9 e 10 foram utilizadas para a validação do modelo empírico. Observa-se que os desvios percentuais dos experimentos antes da reação estiveram abaixo de 5\%, exceto para a amostra 10. Estes percentuais justificam a previsibilidade dos modelos empíricos obtidos para as misturas. Para os lipídios estruturados os desvios percentuais variaram de 12 a $26 \%$. Apesar de apresentar um desvio alto, estes percentuais estiveram dentro dos limites aceitáveis para esta análise, uma vez que foi utilizado um método visual para a medida destas propriedades. 
Para a amostra 10 antes da reação os desvios percentuais dos valores calculados foram de aproximadamente $25 \%$, demonstrando que os componentes desta mistura (gordura do frango e estearina), apesar de presentes em proporções reduzidas, formaram uma matriz cristalina que elevou o ponto de fusão da amostra. Desta forma, os valores analisados pelo método visual apresentaram-se superiores aos calculados pelo modelo. Não foram determinados os pontos de amolecimento e fusão para a amostra 10 após a reação uma vez que o método do tubo capilar não se aplica a esta amostra, devido ao seu baixo ponto de fusão.

Tabela 3. Desvio percentual para os pontos de amolecimento e fusão entre os valores experimentais e os calculados pelos modelos empíricos obtidos pela análise de regressão antes e após a interesterificação

\begin{tabular}{lcccccc}
\hline Amostras & $\begin{array}{c}\text { Ensaio } \\
\text { Experimental }\end{array}$ & \multicolumn{2}{c}{$\begin{array}{c}\text { Valores } \\
\text { calculados pelo } \\
\text { modelo empírico }\end{array}$} & $\begin{array}{c}\text { *Desvio (\%) } \\
\text { entre os valores } \\
\text { experimentais e } \\
\text { os calculados }\end{array}$ \\
\hline Antes & P.A. $\left({ }^{\circ} \mathrm{C}\right)$ & P.F. $\left({ }^{\circ} \mathrm{C}\right)$ & P.A. $\left({ }^{\circ} \mathrm{C}\right)$ & P.F. $\left({ }^{\circ} \mathrm{C}\right)$ & P.A. & P.F. \\
8 & 35,2 & 37,1 & 33,5 & 36,4 & 4,9 & 1,9 \\
9 & 42,0 & 44,7 & 43,8 & 45,9 & 4,3 & 2,7 \\
10 & 28,0 & 32,2 & 21,8 & 24,4 & 22,2 & 24,2 \\
Após & 19,5 & 21,1 & 21,9 & 24,9 & 12,3 & 18,0 \\
8 & 38,5 & 41,2 & 28,5 & 30,6 & 26,0 & 25,7 \\
9 & - & - & - & - & - & - \\
10 & & & & & &
\end{tabular}

Erro $_{\text {relativo }}=\left[\frac{\text { Valor }(\text { observado })-\text { Valor }(\text { previsto })}{\text { Valor }(\text { observado }}\right] * 100=\varepsilon(\%)$

A temperatura final de fusão obtida por DSC pode ser considerada o ponto onde termina o fenômeno da fusão, isto é, o ponto onde todos os cristais passaram para a forma líquida ${ }^{29,30}$. Comparando-se estes valores com os dos pontos de amolecimento e fusão obtidos pelos métodos da AOCS para as amostras originais e suas misturas, observa-se que as temperaturas obtidas por DSC foram sempre superiores àquelas obtidas pela utilização dos tubos capilares, com diferenças para o ponto de fusão variando de 7,1 a $15,4^{\circ} \mathrm{C}$ (média de 10,5 ${ }^{\circ} \mathrm{C}$ ) e para o ponto de amolecimento variando de 4,4 a $12,1^{\circ} \mathrm{C}$ (média de $7,1^{\circ} \mathrm{C}$ ) (Tabela 4). Para os lipídios estruturados as diferenças para o ponto de fusão variaram de 3,4 a $15,9{ }^{\circ} \mathrm{C}$ (média de $9,2{ }^{\circ} \mathrm{C}$ ) e para o ponto de amolecimento variaram de 2,4 a $11,9^{\circ} \mathrm{C}$ (média de $10,4^{\circ} \mathrm{C}$ ) (Tabela 5). A técnica de DSC é sensível e determina em qual temperatura a gordura está completamente no estado líquido, ao contrário de outros métodos subjetivos para determinação do ponto de amolecimento e de fusão, nos quais a olho nu não é possível detectar os cristais menores ainda presentes na amostra. Na determinação do ponto de fusão utilizando DSC, ao contrário do método da AOCS, a amostra cristaliza em uma temperatura muito baixa $\left(-40{ }^{\circ} \mathrm{C}\right)$, que favorece a formação de cristais na forma polimórfica mais estável $(\beta)$, que é caracterizada pela alta densidade e elevado ponto de fusão ${ }^{31,32}$. Além disso, a técnica de DSC permite determinar pontos de fusão de amostras líquidas, tais como TCM e óleos vegetais. Em determinações sucessivas de uma mesma amostra, a técnica de DSC apresenta pequenas diferenças nas temperaturas características, da ordem de 1 a $3{ }^{\circ} \mathrm{C}$. Provavelmente, estas variações se devem à amostragem e não à metodologia em $\mathrm{si}^{30}$.

Foram aplicados modelos de regressão linear simples relacionando os pontos de fusão obtidos por DSC com os pontos de amolecimento e fusão (métodos do capilar aberto e fechado da AOCS) para as misturas e para os lipídios estruturados, cujas equações são
Tabela 4. Comparação entre os pontos de amolecimento e fusão (métodos da AOCS) e pontos de fusão (calorimetria de varredura diferencial - DSC) para as amostras individuais e suas misturas

\begin{tabular}{lccc}
\hline $\begin{array}{l}\text { Amostras } \\
\left(\mathrm{n}^{\circ}\right)\end{array}$ & $\begin{array}{c}\text { Ponto de } \\
\text { amolecimento } \\
\left({ }^{\circ} \mathrm{C}\right)\end{array}$ & $\begin{array}{c}\text { Ponto de } \\
\text { fusão }\left({ }^{\circ} \mathrm{C}\right)\end{array}$ & $\begin{array}{c}\text { Ponto de fusão } \\
\text { determinado por } \\
\text { DSC }\left({ }^{\circ} \mathrm{C}\right)\end{array}$ \\
\hline 1 & 31,8 & 34,2 & 42,4 \\
2 & 44,1 & 47,0 & 51,8 \\
3 & - & - & 1,3 \\
4 & 41,2 & 43,9 & 48,7 \\
5 & 20,0 & 25,3 & 37,4 \\
6 & 38,5 & 41,6 & 48,0 \\
7 & 36,2 & 38,6 & 47,1 \\
8 & 35,2 & 37,1 & 43,9 \\
9 & 42,0 & 44,7 & 49,1 \\
10 & 28,0 & 32,2 & 43,4 \\
\hline
\end{tabular}

Tabela 5. Comparação entre os pontos de amolecimento e de fusão (métodos da AOCS) e pontos de fusão (calorimetria de varredura diferencial - DSC) das amostras individuais interesterificadas e dos lipídios estruturados

\begin{tabular}{lccc}
\hline $\begin{array}{l}\text { Amostras } \\
\left(\mathrm{n}^{\circ}\right)\end{array}$ & $\begin{array}{c}\text { Ponto de } \\
\text { amolecimento } \\
\left({ }^{\circ} \mathrm{C}\right)\end{array}$ & $\begin{array}{c}\text { Ponto de } \\
\text { fusão }\left({ }^{\circ} \mathrm{C}\right)\end{array}$ & $\begin{array}{c}\text { Ponto de fusão } \\
\text { determinado por } \\
\text { DSC }\left({ }^{\circ} \mathrm{C}\right)\end{array}$ \\
\hline 1 & 30,3 & 33,0 & 40,6 \\
2 & 43,1 & 46,3 & 50,6 \\
3 & - & - & 1,1 \\
4 & 35,5 & 38,3 & 47,5 \\
5 & 8,7 & 10,8 & 14,4 \\
6 & 12,3 & 14,7 & 18,0 \\
7 & 17,0 & 18,0 & 20,4 \\
8 & 19,5 & 21,1 & 35,4 \\
9 & 38,5 & 41,2 & 47,4 \\
10 & - & - & $-2,1$ \\
\hline
\end{tabular}

descritas a seguir, empregando o software Statistica, $2002^{19}$.

Para as misturas:

DSC $=7,11+1,07 *$ PA, com coeficiente de correlação $(r)=0,948$ $\mathrm{DSC}=3,96+1,07 * \mathrm{PF}$, com coeficiente de correlação $(\mathrm{r})=0,977$

Para os lipídios estruturados:

DSC $=3,76+1,18 *$ PA, com coeficiente de correlação $(r)=0,976$ $\mathrm{DSC}=1,53+1,15 * \mathrm{PF}$, com coeficiente de correlação $(\mathrm{r})=0,988$

onde: $\mathrm{PA}=$ Ponto de amolecimento $\left({ }^{\circ} \mathrm{C}\right) ; \mathrm{PF}=$ Ponto de fusão $\left({ }^{\circ} \mathrm{C}\right)$; $\mathrm{DSC}=$ Ponto de fusão determinado por calorimetria de varredura diferencial $\left({ }^{\circ} \mathrm{C}\right)$.

Portanto, houve boa correlação [(r) variou de 0,948 a 0,988 ] entre os resultados obtidos para os dois métodos (DSC e AOCS), tanto para as misturas como para os lipídios estruturados.

Nassu e Gonçalves ${ }^{30}$ em estudos sobre pontos de fusão de óleos e gorduras vegetais determinados por calorimetria de varredura diferencial (DSC) e pela metodologia da AOCS (método Cc 3-25), obtiveram que a correlação entre as temperaturas obtidas por estas duas técnicas foi de 0,9856. Esta correlação foi considerada alta e indicadora de boa correlação entre as duas técnicas. Estes resulta- 
dos estão de acordo com os obtidos por Deman et al..$^{33}$ utilizando as técnicas de ponto de gotejamento Mettler e DSC para a determinação do ponto de fusão.

\section{CONCLUSÃO}

Tanto as misturas como os lipídios estruturados contendo gordura de frango, sua estearina e triacilgliceróis de cadeia média apresentaram pontos de amolecimento e fusão dentro de uma ampla faixa, permitindo sua aplicação em uma gama diversa de produtos alimentícios que exijam características específicas quanto a essas propriedades. Houve boa correlação entre os resultados obtidos para os dois métodos (DSC e AOCS), tanto para as misturas como para os lipídios estruturados.

\section{AGRADECIMENTOS}

À Fundação de Amparo à Pesquisa do Estado de São Paulo FAPESP, à Coordenação de Aperfeiçoamento de Pessoal de Nível Superior - CAPES e ao Conselho Nacional de Desenvolvimento Científico e Tecnológico - CNPq, pelo auxílio financeiro e pelas bolsas concedidas aos autores.

\section{REFERÊNCIAS}

1. Petrauskaite, V.; De Greyt, W.; Kellens, M.; Huyghebaert, A.; J. Am. Oil Chem. Soc. 1998, 75, 489.

2. Dian, N. L. H. M.; Sundram, K.; Idris, N. A.; J. Am. Oil Chem. Soc. 2006, $83,739$.

3. Allen, D. A.; Lipid Technol. 1998, 10, 53.

4. Judd, J. T.; Clevidence, B. A.; Muesing, R. A.; Wittes, J.; Sunkin, M. E.; Podczasy, J. J.; Am. J. Clinc. Nutr. 1994, 59, 861

5. Díaz Gamboa, O. W.; Gioielli, L. A.; Ouim. Nova 2006, 29, 646

6. D’Agostini, D.; Gioielli, L. A.; Rev. Bras. Ciênc. Farm. 2002, 38, 345.

7. Gioielli, L. A. Em Entendendo a gordura: os ácidos graxos; Curi, R.; Pompéia, C.; Miyasaka, C. K.; Procópio, J., eds. Manole: São Paulo, 2002, p. 457.
8. Willis, W. M.; Lencki, T. W.; Marangoni, A. G.; Crit. Rev. Food Sci. Nutr. 1998, 38, 639.

9. Padovese, R.; Mancini-Filho, J. Em ref. 7, p. 507.

10. Chiu, M. C.; Gioielli, L. A.; Rev. Bras. Ciênc. Farm. 2002a, 38, 95

11. Chiu, M. C.; Gioielli, L. A.; Ciênc. Tecnol. Aliment. 2002b, 22, 151.

12. Lee K. T.; Foglia T. A.; J. Am. Oil Chem. Soc. 2000, 77, 1027.

13. Hoy, C. E.; Xu, X. Em Structured and Modified Lipids; Gunstone, F. D., ed.; Marcel Dekker: New York, 2001, p. 209.

14. Castro, I. A.; Silva, R. S. F.; Tirapegui, J.; Borsato, D.; Bona, E.; Int. J. Food Sci. Technol. 2003, 38, 103.

15. Box, G. E. P.; Draper, N. R.; Empirical Model-Building and Response Surfaces, John Wiley and Sons: New York, 1987.

16. Chiu, M. C.; Gioielli, L. A.; Grimaldi, R.; Quim. Nova, no prelo.

17. AOCS; Official methods and recommended practices of the American Oil Chemist's Society, Champaign: Illinois, $5^{\text {th }}$ ed., 1998.

18. Hare, L. B.; Food Technol. 1974, 28, 50.

19. Statistica, 2002; Statistica, v.6.0. for window Vol. IV; Statsoft Inc, TulsaOK, USA

20. D’Agostini, D.; Gioielli, L. A.; Ferraz, R. C.; Rev. Port. Farm. 2000, 50, 161.

21. Chiu, M. C.; Gioielli, L. A.; Sotero Solis, V. E.; Grasas y Aceites 2002 , 53, 298.

22. O'Brien, R. D.; Fats and oils: Formulating and processing for applications, Technomic Publishing Co: Lancaster, 1998, p. 47.

23. Sotero Solis, V. E.; Gioielli, L. A.; Polakiewicz, B.; Grasas y Aceites 2000, $51,405$.

24. Díaz Gamboa, O. W.; Gioielli, L. A.; Grasas y Aceites 2003a, 54, 122.

25. Díaz Gamboa, O. W.; Gioielli, L. A.; Grasas y Aceites 2003b, 54, 161.

26. D’Agostini, D.; Ferraz, R. C.; Gioielli, L. A.; Sotero Solis, V. E.; Grasas y Aceites 2001, 52, 214.

27. D’Agostini, D.; Ferraz, R. C.; Gioielli, L. A.; Sotero Solis, V. E.; Alimentaria 2001, 38, 47

28. Sotero Solis, V. E.; Gioielli, L. A.; Polakiewicz, B.; Grasas y Aceites 2001 $52,192$.

29. Nassu, R. T.; Gonçalves, L. A. G.; Grasas y Aceites 1999, 50, 16.

30. Nassu, R. T.; Tese de Doutorado, Universidade Estadual de Campinas, Brasil, 1994

31. Koyano, T.; Sato, K. Em Fats in Food Technology; Rajah, K. K., ed.; Sheffield Academic Press: Kingfield Road, 2002, p. 1.

32. Sato, K.; Ueno, S. Em Crystallization Processes in Fats and Lipid Systems; Garti, N.; Sato, K., ed.; Marcel Dekker: New York, 2001, p. 177.

33. Deman, J. M.; Deman, L.; Blackman, B.; J. Am. Oil Chem. Soc. 1983, 60, 91. 